\title{
LA RECEPCIÓN DE NIETZSCHE \\ EN EL CAMPO FILOSÓFICO DEL TARDOFRANQUISMO: \\ EL CASO DE FERNANDO SAVATER (1970-1974)
}

The Nietzsche Reception in the Philosophical Field of the late Franco's Time:

The Savater Case (1970-1974)

Francisco Vázquez García

Universidad de Cádiz

Resumen: En este artículo se analiza la recepción de la obra de Nietzsche en los escritos filosóficos del joven Fernando Savater (1970-1974). Con este objetivo y desde una perspectiva sociofilosófica, se sitúa la lectura savateriana en el campo filosófico español del tardofranquismo y en el marco de otras lecturas coetáneas de Nietzsche

Palabras clave: Nietzsche, Fernando Savater, filosofía española, tardofranquismo, sociología de la filosofía

ABSTRACT: In this paper, we analyze the reception of Nietzsche's work in the first philosophical writings of Fernando Savater (1970-1974). With this aim and the support of a socio-philosophical approach, we place Savater's reading in the Spanish philosophical field during the late-francoism period and on the background of other contemporary readings of Nietzsche

Key words: Nietzsche - Fernando Savater - Spanish philosophy - Late-francoism Sociology of philosophy

\section{LA CONSAGRACIÓN FILOSÓFICA DE NIETZSCHE EN EL TARDOFRANQUISMO}

En un trabajo reciente se han diferenciado tres tipos de agentes que operaban en el campo filosófico español de las primeras décadas del franquismo. Por una parte estaría el sector, dominado y postergado, representado por los orteguianos liberales, con organismos como el Instituto de Humanidades fundado por el mismo Ortega o pensadores como Julián Marías. Por otro lado se situarían los principales contendientes de este escenario; el conjunto de los falangistas zubirianos (Javier Conde, Gómez Arboleya, Laín Entralgo, Aranguren, el Instituto de Estudios Políticos) y una amplia región, que podríamos denominar «integrista», que englobaría a los pensadores, mayoritariamente eclesiásticos, de las redes tomistas (con el padre Santiago Ramírez como figura principal y el Instituto Luis Vives del CSIC como organismo de referencia), y a los jóvenes nucleados en torno a Rafael Calvo Serer y al grupo Arbor ${ }^{1}$.

1. Agradezco a José Luis Moreno Pestaña haberme dejado consultar los borradores de su libro en preparación, titulado La norma de la filosofía. Para una genealogía del patrón filosófico español, Biblioteca Nueva, Madrid; se trata de un trabajo que ofrece claves fundamentales para entender el periodo en cuestión 
Pues bien en ninguno de estos dos polos —el falangista zubiriano y el integrista- era especialmente relevante la presencia de Nietzsche. En primer lugar, tendía a denegársele el estatuto de filósofo, quedando confinado en el ámbito puramente literario ${ }^{2}$. Por otra parte, desde el sector integrista, como ejemplifica el ensayo Filosofía y Vida. Cuatro ensayos sobre actitudes: Ortega y Gasset, Croce, Nietzsche y Unamuno (1946), del suareciano Juan Roig Gironella, jesuita y director de la revista Pensamiento, la aportación teórica de Nietzsche era rechazada por su biologicismo ateo $^{3}$, mientras que algunos intelectuales falangistas como el joven Laín Entralgo o Montero Díaz, siguiendo una tradición anterior a la Guerra Civil (Giménez Caballero, Ledesma Ramos) reivindicaban a Nietzsche como ideólogo prefascista ${ }^{4}$.

Esta situación comenzó a quebrarse con la emergencia, en la primera mitad de la década de los sesenta, de una lectura erudita de Nietzsche que apuntaba a consagrar su obra afrontándola como contribución genuinamente filosófica. Esta empresa prendió en un grupo de jóvenes católicos formados teológicamente en Austria y Alemania entre finales de los años cincuenta y comienzos de los sesenta 5 . Compartiendo la misma experiencia histórica, esto es, la novedad que en el campo religioso supuso el concilio Vaticano II $^{6}$, estos pensadores defendieron la apertura de la filosofía española a las corrientes de la modernidad intelectual europea ${ }^{7}$. En

2. Un relevante filósofo del sector integrista (formado en el grupo Arbor y colaborador asiduo de la Revista de Filosofía del CSIC), Oswaldo Market (nacido en 1927), declaró en una entrevista que Así habló Zaratustra había sido su libro de cabecera durante años, considerando no obstante que su interés era puramente literario y clasificando a Nietzsche como poeta, junto a Rilke. Market ha sido asimismo miembro de la Europäische Nietzsche Gesellschaft (AA.VV., Dinâmica do pensar. Homenagem a Oswaldo Market, Universidade de Lisboa, 1991, p. 305).

3. Cf. G. Sobejano, Nietzsche en España, 1890-1970, Madrid: Gredos, 2004, p. 635. Entre los manuales del curso de Filosofía Tomista editado por Herder — de amplia circulación en la Universidad española de los años sesenta-, merece mencionarse el volumen dedicado a la filosofía contemporánea, obra de R. Verneaux. En el capítulo dedicado al pensamiento de Nietzsche -que expone en cierto modo la versión escolar y rutinizada de este autor en el ámbito de la escolástica oficial— se señala: «su doctrina está íntimamente relacionada con la de Darwin, de quien adopta tres principios: la evolución, la lucha por la vida y la supervivencia del más fuerte» (R. Verneaux, Historia de la Filosofía Contemporánea, Barcelona: Herder, 1966, p. 59).

4. G. Sobejano, op. cit., pp. 650-663 y J. Rodríguez Puértolas, Historia de la literatura fascista española, 2 vols., Barcelona: Akal, 2008, pp. 117, 221, 492, 670 y 1077.

5. Una descripción, no exenta de humor, de este medio de aprendices españoles de teología formados en el mundo germánico puede verse en M. Vicent, Aguirre el magnifico, Madrid: Santillana, 2011, pp. 109-125.

6. Sobre la repercusión del Vaticano II en España y sobre la posterior politización de la teología («el 1968 teológico»), cf. O. González de Cardedal, La teología en España (1959-1909). Memoria y prospectiva, Madrid: Encuentro, 2010, pp. 55-71.

7. Curiosamente, la literatura dedicada a indagar la recepción de Nietzsche en España, apenas ha reparado en este grupo, aunque se mencionen sus trabajos. Cf. G. Sobejano, op. cit., pp. 667-683; D. Sánchez Meca, «Nietzsche en España», en M. Garrido, N. R. Orringer, L. M. Valdés y M. M. Valdés (coords.), El legado filosófico español e hispanoamericano del siglo XX, Madrid: Cátedra, 2009, pp. 970-971; T. Oñate, «Diálogo con Vattimo", en G. Vattimo, Diálogo con Nietzsche, Barcelona: Paidós, 2002; M. Cruz, "Nietzsche: un espejo a lo largo del camino», en Siempre me sacan en página par, Barcelona: Paidós, 2007, pp. 210-213, y A. Morillas, «Apuntes sobre la edición en español de los textos de F. Nietzsche»: Papeles del Seminario María Zambrano 10 (2009), 105-111. Tampoco en la literatura que reconstruye la trayectoria intelectual de Savater, por ejemplo en el excelente trabajo de M. Nogueroles Jové, La trayectoria intelectual de Fernando Savater: el pensamiento crítico de un 'joven filósofo', Tesis Doctoral leída en la Universidad Autónoma de Madrid, Madrid, 2010, o en el más superficial de G. Plata Parga, «Fernando Savater. El azar y el amor propio», en De la revolu- 
esta «unidad generacional $»^{8}$ y en relación con la recepción de la obra de Nietzsche, destacaron tres nombres, todos ellos muy vinculados al despegue, desde 1963, de las Convivencias de Filósofos Jóvenes, que pretendían plasmar esta nueva apertura. Se trata de Álvarez Bolado, Andrés Sánchez Pascual y Luis Jiménez Moreno. Junto al catolicismo avanzado, los tres compartían una posición académica relativamente periférica y precaria. El primero, joven jesuita ligado al aggiornamiento filosófico de la revista Pensamiento, animador principal del diálogo con el ateísmo, fue uno de los primeros conocedores españoles de los cursos de Heidegger sobre Nietzsche, editados en 1961. Introductor de las nuevas teologías anglosajonas y centroeuropeas, entre ellas la teología de «la muerte de dios», de William Hamilton, Álvarez Bolado se aproxima a Nietzsche desde una clave ontológica inspirada por la meditación heideggeriana acerca de la historia del ser9. Por su parte, Luis Jiménez Moreno y Andrés Sánchez Pascual, dotados también de un importante capital teológico y vinculados al impulso inicial de las Convivencias de Filósofos Jóvenes, contribuyeron, con su labor de erudición e interpretación, a la consagración de Nietzsche en la esfera de la filosofía profesional. El primero, colaborador asiduo de la revista Aporía, que en su corta existencia (1964-1967) trabajó para dar a conocer las corrientes contemporáneas a la audiencia filosófica española, editó en la mencionada publicación, diversos artículos sobre Nietzsche (entre ellos, en 1964, una de las primeras reseñas del Nietzsche de Martin Heidegger), realizados desde una antropología filosófica de corte personalista. Esta tarea culminó con una monografía publicada por Labor en 1972 y con la traducción de El gay saber para la editorial Narcea, en $1973^{10}$.

Andrés Sánchez Pascual, que contaba con una formación filosófica y teológica completada en Austria y en Alemania, se interesó, como Álvarez Bolado, por el diálogo con las nuevas teologías protestantes, publicando, en la primera mitad de los años sesenta, diversos ensayos sobre el asunto, en particular sobre las figuras del luterano Joseph Lortz y del católico Romano Guardini. Por otro lado, en los mismos años, ejerció como asiduo recensor de monografías filosóficas (especialmente en lengua alemana) en la Revista de Filosofía del CSIC. En 1966 tradujo en Alianza Editorial el estudio de Eugen Fink sobre Nietzsche y poco

ción a la sociedad de consumo. Ocho intelectuales en el tardo franquismo y la democracia, Madrid: UNED, 2010, pp. 187-216, se atiende a esta tendencia. En ninguno de estos análisis se sitúan las lecturas de Nietzsche en el campo filosófico español de la época, optándose por un enfoque idiográfico (del tipo «el autor y su obra»). Nuestro trabajo, realizado desde la sociología de la producción filosófica, explora el caso particular emplazándolo en el espacio de las alternativas «composibles».

8. Sobre la distinción, originariamente establecida por Karl Mannheim, entre «localización generacional», «unidad generacional» y «complejo generacional», cf. K. Mannheim, «El problema de las generaciones»: Revista Española de Investigaciones Sociológicas (REIS) 62 (1993), 193-242.

9. Sobre el papel desempeñado por Álvarez Bolado en la recuperación española de Nietzsche, cf. F. Vázquez García, La Filosofía española. Herederos y pretendientes. Una lectura sociológica (1963-1990), Madrid: Abada, 2009, pp. 203-204.

10. Jiménez Moreno leyó en 1962 y en la Universidad Complutense de Madrid su tesis doctoral (dirigida por Aranguren), titulada El pensamiento antropológico de Nietzsche. Siendo profesor en la Facultad de Filosofía de la Universidad de Barcelona, publicó en la «nueva colección» de Labor la monografía Nietzsche (1972). En la «presentación» de esta obra dejaba constancia del carácter académico de la misma frente a la moda nietzscheana que hacía furor en esos años: «Y sobre todo he querido dejar aparte entusiasmo o aversión directamente por lo nietzscheano» (L. Jiménez Moreno, Nietzsche, Barcelona: Labor, 1972, p. 6). 
después - contando ya con el nuevo trabajo de edición del corpus nietzscheano iniciado por Colli y Montinari en $1961^{11}$ - se responzabilizaría del proyecto de Alianza Editorial para publicar, en edición de bolsillo con notas e introducciones, la totalidad de las obras del filósofo de Röcken, vertidas al castellano. Como es sabido, la serie se estrenó con Ecce Homo, que vio la luz en 1971.

Sobre este trasfondo, y en parte contra él, se localiza entre el final de la década de los sesenta y comienzos de los setenta, una nueva recuperación de la herencia nietzscheana desde una perspectiva que se pretendía creativa y no meramente erudita. Los protagonistas de esta empresa, entre los que destacan Eugenio Trías y Fernando Savater, componen una emergente unidad generacional marcada, no ya por las secuelas del Vaticano II sino por la experiencia compartida de las revueltas de Mayo del 68 en su repercusión española, particularmente en el ámbito de la contestación estudiantil y del movimiento de jóvenes profesores universitarios no numerarios. Esta recepción se apoya en buena medida en las lecturas vanguardistas de Nietzsche que venían realizándose en Francia desde los años treinta, en círculos próximos al surrealismo y al Collège de Sociologie fundado por Georges Bataille. La estela de estas lecturas alcanzó su momento culminante en la década de los sesenta y primeros años setenta, con los trabajos de Deleuze, Foucault, Blanchot y Derrida ${ }^{12}$. Estas interpretaciones de vanguardia - crecientemente izquierdistas tras las revueltas del sesenta y ocho- coexistían, en Francia, con aproximaciones de corte más académico tendentes a la sistematización del pensamiento nietzscheano ${ }^{13}$.

En España se produjo por tanto una polaridad semejante a la del país vecino; ${ }^{14}$ de un lado un enfoque erudito - muy marcado en el caso español por el catolicismo teológicamente avanzado- que pretendía entronizar a Nietzsche entre los clásicos modernos de la filosofía y que miraba hacia las serias interpretaciones alemanas (Löwith, Fink, Jaspers, Heidegger); del otro una recepción vanguardista que se valía de Nietzsche para cuestionar el orden establecido, rivalizando al mismo tiempo con las otras alternativas —en particular el análisis y la crítica marxista de las ideologías- que pugnaban por ocupar el espacio filosófico abandonado - en el plano teórico, no en el institucional— por los representantes de

11. Cf. G. Campioni, Leggere Nietzsche. Alle origini dell'editzione critica Colli-Montinari, Pisa: ETS Editrice, 1992.

12. El escritor Pere Gimferrer, refiriéndose a ese «triunfal retorno» a Nietzsche en España y mencionando el volumen colectivo A favor de Nietzsche y las traducciones de Alianza, insistió, no obstante, en el carácter endógeno del acontecimiento: «Y no se crea que son los exégetas, llámense Deleuze o Klossowski, quienes lo hacen posible» (P. Gimferrer, "El retorno de Hermann Hesse»: Destino n. ${ }^{\circ} 1852,31.3 .1973$, p. 35). De hecho, el retorno — aunque mucho más discreto- se había producido antes, con el trabajo de los eruditos-teólogos ya mencionados.

13. Sobre las lecturas francesas de ese periodo, cf. L. Pinto, Les neveux de Zarathoustra. La réception de Nietzsche en France, Paris: Seuil, 1995, pp. 121-197, y J. Le Rider, Nietzsche en France. De la fin du XIXe siècle au temps présent, Paris: PUF, 1999, pp. 205-244. Un estado de la cuestión en L. Verbaeke, «L'histoire de la réception de Nietzsche en France. Bilan critique»: Revue de Littérature Comparée 2 (2003), 225-233. La mediación francesa del Nietzsche recuperado por los neonietzscheanos españoles ha sido subrayada por D. Sánchez Meca, loc. cit., p. 958.

14. Una comparación sociológica entre la lectura, prototípicamente erudita y sistematizadora, de Jean Granier (Le problème de la vérité dans la philosophie de Nietzsche, tesis leída en 1964) y la más vanguardista de Gilles Deleuze (Nietzsche et la philosophie, publicada en 1962), puede encontrarse en L. Pinto, op. cit., pp. 182-184. 
la escolástica oficial. En este caso el punto de mira lo constituían las lecturas francesas, más creativas y literarias (Bataille, Klossowski y en menor medida Deleuze). Lo que en su momento se conoció como «neonietzscheanismo» o «filosofía lúdica» fue el resultado de esta recepción vanguardista o experimental.

Esta polaridad, eventualmente convertida en antagonismo, no implicaba una falta de relación e incluso de colaboración entre eruditos y vanguardistas. Eugenio Trías, por ejemplo, poseedor desde muy pronto, de un sólido capital histórico-filosófico de corte clásico (Platón, idealismo alemán, Heidegger), accedió a la obra de Nietzsche a través de la aproximación erudita y ontológica de Álvarez Bolado. Estas hechuras se advierten, por ejemplo, en la ponencia que presentó, con apenas 23 años de edad, en la quinta edición de las Convivencias de Filósofos Jóvenes, celebradas en 1967 en Alcalá de Henares. Esta intervención, que supuso la entronización de Trías en la comunidad filosófica española, mostraba la combinación de competencias propias de un docto especialista en Historia de la Filosofía, con disposiciones para evocar, sugerir e incluso profetizar, más afines al perfil de un ensayista ${ }^{15}$. El caso de Fernando Savater es diferente; desprovisto de los recursos derivados de la erudición histórica, se encontraba dotado de una al tiempo vasta y dispar cultura literaria, mezcla de literatura "popular» (Lovecraft, Tolkien, Kipling, Stevenson, Julio Verne, Salgari) y de clásicos revalorizados por la vanguardia (Beckett, Borges, Poe, Melville). Estos elementos coaligados con el magisterio oral de Agustín García Calvo, las lecturas de los filósofos frankfurtianos recomendadas por Jesús Aguirre (otro teólogo de avanzada), la temprana familiaridad con El Mundo como Voluntad y Representación y la frecuentación de cierta «sombra» de la filosofía oficial francesa -Cioran, Clément Rosset, Bataille y Klossowski, principalmente- desembocaron en un acercamiento radicalmente antiacadémico a la obra de Nietzsche ${ }^{16}$. Nuestro trabajo se centrará en este último caso.

\section{UN NIETZSCHE «AFRANCESADO»: EN LA ESTELA DEL COLLÈGE DE SOCIOLOGIE}

Pierre Bourdieu y sus discípulos han mostrado de qué manera la creación de una nueva opción en el espacio de posibles que conforma el campo filosófico, implica una ruptura de las jerarquías establecidas entre los géneros y los bienes simbólicos que circulan en él, una desacralización del canon vigente y la consagración de un nuevo canon ${ }^{17}$. Por su parte, Randall Collins se ha referido a las interacciones rituales a través de las cuales estos bienes (textos, autores y argumentos en este caso) se cargan de «energía emocional», conviertiéndose en objeto de culto y veneración ${ }^{18}$.

15. Cf. F. Vázquez García, «Rituales de interacción y especies de capital en el nietzscheanismo español (1968-1976)»: Daimon. Revista de Filosofía (en prensa).

16. Sobre las fuentes de Savater, cf. M. Nogueroles Jové, La trayectoria intelectual de Fernando Savater: el pensamiento crítico de un 'joven filósofo', cit., pp. 35-58.

17. P. Bourdieu, La ontología política de Martin Heidegger, Barcelona: Paidós, 1991; J. L. Fabiani, Les philosophes de la république, Paris: Minuit, 1988; L. Pinto, La théorie souveraine. Les philosophes français et la sociologie au XXe siècle, Paris: Cerf, 2009, y L. Pinto, La vocation et le métier de philosophe. Pour une sociologie de la philosophie dans la France contemporaine, Paris: Seuil, 2007.

18. R. Collins, Cadenas de rituales de interacción, Barcelona: Anthropos, 2009. 
Las intervenciones de Fernando Savater en el periodo temprano de su trayectoria intelectual, que toman como referencia explícita la obra de Nietzsche, trátese de conferencias, artículos, reseñas, traducciones o notas de edición, pueden entenderse como otros tantos rituales destinados a consagrar a Nietzsche como emblema de una nueva opción intelectual y de un nuevo grupo de creadores en el campo filosófico español.

Nos centraremos en el periodo 1970-197419, que constituye el momento de despegue de esta nueva e inesperada alternativa. ¿Cómo preservar la singularidad de Nietzsche como pensador sin hacerle perder su legitimidad filosófica relegándolo al ámbito de la ensoñación literaria? Esta era la cuestión. Se trataba de rechazar la rutinización académica de Nietzsche, su canonización como clásico de la filosofía, trabajo emprendido por las lecturas eruditas mencionadas con anterioridad. Se pretendía en cambio reivindicar su condición literaria, pero no, como hasta entonces habían hecho los filósofos profesionales españoles del periodo franquista, con objeto de excluir su interpelación en el terreno del pensamiento, sino precisamente para vindicar el ejercicio literario y la voluntad de estilo como las formas más genuinas de crítica y creaicón filosófica. La entronización de Nietzsche implicaba por tanto una subversión en la jerarquía de los géneros establecidos — donde el decir verdadero del filósofo primaba sobre el decir ficticio del escritor-y una propuesta de hibridación entre la experimentación literaria y la expresión filosófica.

Aunque la referencia a Nietzsche es una constante en la temprana producción intelectual de Fernando Savater, puede deslindarse un corpus de intervenciones que afrontan explícitamente la reflexión sobre y a partir de la obra de Nietzsche. Se trata de un conjunto formado por tres conferencias (dos de ellas pronunciadas en Madrid y la tercera en Zaragoza) ${ }^{20}$, un artículo publicado en Tiempo de Historia $^{21}$, dos trabajos de edición y traducción ${ }^{22}$, cinco reseñas publicadas en Triunfo ${ }^{23}$ $\mathrm{y}$ una nota polémica ${ }^{24}$ editada en esta misma revista.

Cuando publicó sus dos primeros libros, Nibilismo y Acción y La Filosofía Tachada, ambos en 1970, Fernando Savater había frecuentado muy poco la obra de Nietzsche ${ }^{25}$. Fue sólo con posterioridad cuando emprendería una lectura más

19. Este intervalo coincide aproximadamente con lo que Marta Nogueroles identifica como la primera etapa del "periodo hipercrítico» de Savater, centrada en el cuestionamiento de la filosofía oficial. Cf. M. Nogueroles Jové, La trayectoria intelectual de Fernando Savater, cit., pp. 69-112.

20. F. Savater, «Apología del sofista», en Apología del sofista, Madrid: Taurus, 1973, pp. 34-42; F. Savater, "Cincuenta palabras de Federico Nietzsche», en E. Trías y otros, En favor de Nietzsche, Madrid: Taurus, 1972, pp. 133-176, y F. Savater, «Nietzsche en casa de Circe», en Escritos politeístas, Madrid: Editora Nacional, 1975, pp. 49-62.

21. F. Savater, «Nietzsche: vida de un seductor»: Tiempo de historia 1 (diciembre de 1974), 48-63, reed. en Escritos politeístas, cit., pp. 83-112.

22. F. Savater, «Prólogo» a F. Nietzsche, Inventario, ed. de F. Savater, Madrid: Taurus, 1973, pp. 9-15; F. Savater, «Prefacio» a G. Bataille, Nietzsche. Voluntad de suerte, trad. de F. Savater, Madrid: Taurus, 1972, p. 11.

23. F. Savater, «Y ahora, Nietzsche»: Triunfo 489 (11.12.1971), p. 55; F. Savater, «Klossowski traza un círculo»: Triunfo 518 (2.9.1972), p. 44; F. Savater, «El ciclo Nietzsche en el Instituto Alemán»: Triunfo 533 (16.12.1972), p. 61; F. Savater, «Nietzsche como pretexto»: Triunfo 538 (20.1.1973), p. 53; F. Savater, «El alma y los griegos»: Triunfo 581 (17.11.1973), pp. 81-82.

24. F. Savater, «Nietzsche, la escuela de Frankfurt, Mayo 68...»: Triunfo 541 (10.2.1973), p. 39.

25. En el Prólogo a la reedición conjunta de ambos textos, en 1978, se señala que «cuando escribí Nihilismo y acción no había leído prácticamente nada de Nietzsche y muy poco al pergeñar $L a$ 
detenida y exhaustiva. No obstante, ya en esos primeros textos, que le valdrían a Savater la calificación de «neonietzscheano», por parte de la crítica, se advierte la presencia del autor de Así habló Zaratustra. Aquí ocupa un lugar fundamental, como argumento vertebrador, la oposición trágica entre vida y cultura: el mundo occidental moderno habría dado lugar a una cultura objetiva, constituida por un orden autónomo de formas, inaccesible e independiente respecto a la subjetividad individual, hasta el punto de que esta acabaría convirtiéndose en instrumento de aquella. Lo trágico de la situación residiría en el hecho de que estas formas culturales enajenadas de su raíz y en último término negadoras de la vida, habrían brotado de la misma vida.

Este argumento, fundado a partir del diagnóstico nietzscheano acerca del nihilismo como destino de Occidente, habría llegado a Ortega — sobre todo al Ortega más nietzscheano, el de El tema de nuestro tiempo $(1923)^{26}$ - a través de Simmel ${ }^{27}$. Lo curioso es que Savater no retoma esta antítesis de Ortega -un autor apenas presente en la obra temprana del vasco- sino, en primer lugar, de los pensadores de la escuela de Frankfurt —en particular Adorno, Horkheimer y Marcuse-, bajo la forma del antagonismo entre razón sustancial y razón formal, entre dialéctica negativa y positivismo ${ }^{28}$. En segundo lugar, Savater asimila la antítesis vida/cultura a la distinción, forjada por Durkheim y Mauss y reelaborada por los escritores franceses del Collège de Sociologie (Bataille y Klossowski en particular), entre lo sacro y lo profano ${ }^{29}$. La esfera de lo profano coincide con el orden de los fenómenos «homogéneos» ligados al principio de utilidad: el trabajo, el cálculo, la ley, la servidumbre. La esfera de lo sacro tiene que ver con los fenómenos «heterogéneos» de nuestras sociedades, vinculados al principio de pérdida: el juego, el derroche y el azar (evocado por Savater a través de Bataille pero también de Cioran y Clément Rosset), la transgresión, la soberanía. En esta misma filiación con el Collège de Sociologie (Bataille, Klossowski, el surrealismo) y su fascinación por lo nocturno, se entiende la frecuente evocación de Sade y una cierta exaltación de aquellos elementos de la cultura hispánica (desde la tauromaquia hasta la mística) cuya «heterogeneidad» será precisamente celebrada por estos pensadores franceses ${ }^{30}$. El hecho de estar situados al margen de las

Filosofía tachada» (F. Savater, La filosofía tachada, precedida de Nibilismo y acción, Madrid: Taurus, 1978, p. 8). En F. Savater, «Nietzsche como pretexto», cit., se refiere, no obstante, a la «lectura precoz del Zarathustra».

26. J. Ortega y Gasset, El tema de nuestro tiempo, Madrid: Revista de Occidente, 1961, pp. 43-50.

27. Cf. F. Gil Villegas, Los profetas y el mesías. Lukács y Ortega como precursores del Heidegger en el 'Zeitgeist' de la modernidad (1900-1929), México: FCE, 1996.

28. Cf. F. Savater, Nibilismo y acción, cit., p. 20, sobre Marcuse; La filosofía tachada, cit., pp. 9697, sobre Adorno; pp. 101, 134-137, sobre Horkheimer; pp. 122-124, sobre Adorno y Horkheimer

29. Cf. D. Hollier, El Colegio de Sociología, Madrid: Taurus, 1982.

30. Esta celebración es bien conocida en el caso de Bataille (cf. P. Mayayo, «Bataille: imágenes de España", en Íd. [ed.], En torno a Georges Bataille, Madrid: Cruce, 1998, pp. 125-152). Por su parte, Pierre Klossowski, en cierta ocasión a comienzos de los setenta, le comentó a Savater su extrañeza ante la imposibilidad, debido a la censura, de vertir al castellano sus novelas, pues, por ejemplo, «Le Baphomet está escrita con una visión de la religión muy próxima a la española» (F. Savater, «Por Francia, del vino a la filosofía»: Triunfo [29.12.1973], p. 43). En cuanto a Clément Rosset, quizás deba recordarse que le concede un importante papel al pensamiento de Gracián en su obra La anti-naturaleza, Madrid: Taurus, 1974. Sobre la admiración de Cioran por España («hemos llevado a su límite la experiencia de vivir»), cf. F. Savater, «Sobre E. M. Cioran», en E. M. Cioran, Breviario de podredumbre, Madrid: Taurus, 1988, p. 16. 
coacciones de carrera establecidas en el campo filosófico profesional (algo que no sucedía con Foucault, Deleuze y Derrida), le permitía a estos autores adoptar, como ha señalado Louis Pinto ${ }^{31}$, una actitud de audacia extrema. El menosprecio de los valores académicos y escolares, cuyas raíces sociales en Savater han sido analizadas en otro lugar ${ }^{32}$, con la exaltación de la diferencia y de lo sublime frente a la mediocridad y la rutina encorsetada, conduce a nuestro autor a optar por el «Nietzsche» menos universitario, representado por los nombres de Klossowski, Bataille y Cioran ${ }^{33}$.

Estas claves argumentales, forjadas por Bataille, se conectan, por otro lado, con una reflexión sobre el lenguaje y sobre los usos críticos de la literatura. Aquí aparece en primer lugar la referencia a un Klossowski recombinado con los planteamientos de García Calvo y de Cioran: el lenguaje tal como está establecido constituye el espacio de lo homogéneo, de las identidades reconocibles y recortadas por los conceptos, donde rige la linealidad teleológica y el progreso, el yo estable, la primacía de la eficacia comunicativa y la obediencia al Estado. Aquí se hace presente el dictum nietzscheano - evocado por Savater con posterioridad: «no nos vamos a desembarazar de Dios porque creemos aún en la Gramática»—34. ¿Cómo es posible entonces una crítica del lenguaje ejercida a través del propio lenguaje? Aquí se inscribe el esfuerzo de Savater para recuperar una escritura liberada de toda función pedagógica ligada a la transmisión, a la comunicación, al discurso científico. La filosofía es un género literario que no pretende transmitir ningún contenido ni enseñar nada; es experiencia (aquí resuena la noción de «experiencia interior» forjada por Bataille) ${ }^{35}$ antes que enseñanza («enseñar lo inenseñable», en la fórmula acuñada por Klossowski), una experiencia del vacío, de la inanidad del ser, de la ausencia de fundamento (aquí se retoma el tema de la «lucidez» abierto por Cioran); una labor extrema de destrucción de ídolos, de disolución de las identidades solidificadas por el lenguaje. Esta tarea pone en evidencia las fisuras reprimidas por el orden conceptual, positivo y monoteísta — donde el lugar de Dios es ocupado sucesivamente por el Progreso, la Ciencia, el Estado o incluso por la celebración contracultural del erotismo o de la embriaguez ${ }^{36}$ - que constituye nuestra cultura. La exploración

31. L. Pinto, Les neveux de Zarathoustra, cit., p. 110.

32. F. Vázquez García, La filosofía española, cit., pp. 264-313.

33. Sobre la preferencia de Savater por el estilo de Cioran antes que por el de Bataille, cf. F. Savater, Mira por dónde, Madrid: Taurus, 2003, p. 232. Sobre la difícil relación entre el pensamiento de Cioran y el de Nietzsche, cf. F. Savater, «Sobre E. M. Cioran», cit., p. 13.

34. F. Savater, "Cincuenta palabras de Federico Nietzsche», p. 157. Esta caracterización de la filosofía como purga de la gramática-teología le permite a Savater emparentar las empresas de Nietzsche y de Wittgenstein, argumento que ya aparece en La filosofía tachada, cit., pp. 163-164.

35. En 1972, Savater tradujo para la editorial Taurus el libro de Bataille sobre Nietzsche, ya mencionado; un año después hizo lo propio con La experiencia interior, y su intención era finalizar la versión castellana de la tríada que componía la Summa atheologica de Bataille, traduciendo Le Coupable, tarea que finalmente completó en 1979. Cf. F. Savater, La filosofía tachada, cit., pp. 123-124, 132, 164.

36. La actitud de Savater ante lo que se conoció desde finales de los sesenta como movimiento de la "contracultura», es ambivalente. Estima lo que tiene de espíritu de revuelta para subvertir el orden vigente, pero cuestiona su conversión en un rótulo más de la industria cultural y su afinidad con un pensamiento «positivo» y acrítico, tendente a celebrar con autocomplacencia moralizante las bondades de la "Naturaleza», del «juego» o de la «liberación sexual», nuevas máscaras del Dios monoteísta. Cf. F. Savater, «Cuerpo, amor, silencio»: Triunfo 559 (16.6.1973), pp. 48-49; F. Savater, «La cultura como forma de hastío», en Escritos politeístas, cit., p. 75. Las reticencias de Savater ante 
experimental del lenguaje, la voluntad de estilo traduce esa preocupación por la escritura como experiencia de desfundamentación, que aúna la actividad filosófica - v.g. la indagación nietzscheana de estilos diversos, desde el tratado y el aforismo hasta el poema - con la literaria, sea en sus modalidades formalmente más audaces (Samuel Beckett) o en su perfil más clásico (Borges).

En Nibilismo y Acción se hacen valer sobre todo las referencias frankfurtianas y el escepticismo de Cioran y de Rosset, para defender un quehacer filosófico entendido en términos estrictamente negativos y trágicos, un «filosofar con el martillo» destronador de los ídolos que pretenden justificar la vida y que conmina a actuar prescindiendo de todo fundamento donador de sentido. En $\mathrm{La} \mathrm{Fi}$ losofía tachada (que se vendía abrazada por una banda rotulada como «una purga de la filosofía académica»), la destrucción se dirige principalmente contra el ejercicio académico de la filosofía. Este actúa legitimando la subordinación del pensamiento al orden de lo pedagógicamente transmisible, lo socialmente útil y lo administrable por parte del Estado. En este texto, la referencia a una apropiación creativa y artística de Nietzsche por parte de Bataille y de Klossowski (y en menor medida de Deleuze) es mucho más explícita e intensa que en Nibilismo y Acción.

Esta misma presencia de las lecturas francesas que convierten a Nietzsche en el pensador de la «diferencia libre» (Deleuze), de lo «heterogéneo» (Bataille), del «juego circular de los simulacros» (Klossowski) y del «azar» (Rosset), frente a la nivelación de la experiencia estipulada por la moral y el cientificismo, se hace patente en las diversas intervenciones de Savater que toman como asunto o como pretexto explícito, la obra del pensador de Röcken. En más de una ocasión Savater llega a considerar Nietzsche y el círculo vicioso, publicado originalmente en 1969 y vertido al castellano en 1972, por la editorial Seix Barral, como «uno de los más grandes libros de filosofía de la posguerra europea» ${ }^{37}$.

Otra estrategia argumentativa de importación francesa consistía en contraponer el pensamiento afirmativo de Nietzsche a la exaltación hegeliana de la negatividad. Hegel había elevado a concepto el orden establecido, asentado en la productividad y el Estado y petrificado en el lenguaje. Lo habría hecho en la forma de una historia reconciliada de la razón, movilizada por la fuerza de lo negativo. Nietzsche quedaría entonces enfrentado a Hegel, como encarnación de todo aquello que se rebela contra el poder integrador del decurso dialéctico.

El primer valedor de este singular combate fue Georges Bataille. Desde la fundación de la revista Acéphale (1936-1939), este escritor contribuyó a reemplazar la tradicional oposición académica entre Kant y Nietzsche por el antagonismo entre Nietzsche y Hegel. La frecuentación de los cursos de Kojève y la lectura de sus textos condujo a Bataille hacia una suerte de «hegelianismo negro», que sería en realidad una subversión de la filosofía hegeliana. Esta toma la forma de una historia homogénea de la razón; Nietzsche en cambio supone el retorno de las fuerzas heterogéneas, lo sublime trágico que no puede ser integrado en los dominios de la utilidad y del Estado ${ }^{38}$. La monografía de Deleuze sobre Nietzsche continuará

los ensayos publicados por Rubert de Ventós en esta época tienen que ver con el mismo motivo, cf. F. Savater, «El ensayo del día está al día»: Triunfo 622 (31.8.1974), p. 39.

37. F. Savater, «Klossowski traza un círculo», cit., p. 44, y F. Savater, "Filosofía», en «El libro de feria en feria. Novedades 1972-73»: Cuadernos para el Diálogo 116 (mayo de 1973), p. X.

38. J. Le Rider, Nietzsche en France, cit., pp. 163-170. 
este mismo argumento añadiéndole un nuevo motivo; la pugna entre las fuerzas reactivas cuya expresión intelectual sería la dialéctica y el primado de la negación, y las fuerzas activas, trasunto de la «diferencia» y de su poder de afirmación ${ }^{39}$.

Savater recoge cumplidamente este argumento $^{40}$. Por un lado cuestiona, o al menos atenúa la oposición clásica entre Kant ${ }^{41}$ — prototipo de pensador académico- y Nietzsche - modelo de profetismo iconoclasta - y centra su atención en el choque estelar entre el visionario de Sils-Maria y el rector de la Universidad de Berlín ${ }^{42}$. La iniciación de Savater en los aledaños de la filosofía hegeliana le vino principalmente de la lectura y frecuentación de su amigo Antonio Escohotado, que a comienzos de los setenta ${ }^{43}$, poco antes del célebre seminario sobre Nietzsche en la Universidad Autónoma de Madrid —rito fundacional del grupo neonietzscheano español - había dirigido en la misma Universidad un seminario sobre Hegel.

Precisamente, y es un asunto en el que no podemos extendernos, las limitaciones que Savater advertía en el proyecto crítico de los mejores pensadores frankfurtianos - tan influyentes en las primeras obras del filósofo vasco- tenían que ver con su excesivo apego a la dialéctica - y su ceguera para la «diferencia», su incomprensión del alcance cuestionador inherente a la filosofía nietzscheana y su apego a las formas de transmisión universitaria- ${ }^{44}$. Este rechazo radical del academicismo es quizás el rasgo más notorio de la lectura savateriana, y enlaza con la incompatibilidad entre Nietzsche y el filósofo con vocación de enseñar, un rasgo resaltado por Klossowski y adoptado fielmente por el pensador español.

\section{UN NIETZSCHE ANTIACADÉMICO}

La importación y consagración filosófica de la obra de Nietzsche por parte de Savater se sitúa, en el campo filosófico español de su momento, contra la tentativa iniciada por los miembros de una unidad generacional anterior (Álvarez Bolado, Jiménez Moreno, Sánchez Pascual), para entronizar el corpus nietzscheano en el canon de los clásicos de la filosofía. Esta empresa es recusada por Savater, que considera a Nietzsche como «el pensador más intratable del siglo XIX $»^{45}$, im-

39. L. Pinto, Les neveux de Zarathoustra, cit., pp. 124-125.

40. «[...] y al fondo constantemente, Hegel y Nietzsche, Hegel contra Nietzsche, Nietzsche contra Hegel» (F. Savater, «Y ahora, Nietzsche», cit., p. 55).

41. L. Pinto, Les neveux de Zarathoustra, cit., pp. 32-33.

42. Aludiendo a la crítica de Kant por Nietzsche, Savater señala que «la figura misma de Kant no fue tan indiscutiblemente filistea como Nietzsche la pinta» (F. Savater, «Kant y el reino de la libertad»: Triunfo 638 [21.12.1974], p. 59)

43. F. Savater, «Hegel. Filosofía y religión»: Triunfo 529 (18.11.1972), pp. $64-65$ (se trata de una reseña del libro de A. Escohotado, La conciencia infeliz. Ensayo sobre la filosofía de la religión de Hegel, Madrid: Revista de Occidente, 1972). Sobre las reuniones de juventud en casa de Antonio Escohotado para beber, fumar yerba y hablar «de Hegel o Heidegger», cf. F. Savater, Mira por dónde, cit., p. 211.

44. Sobre estas limitaciones, cf. F. Savater, «Una disputa fundamental»: Triunfo 536 (6.1.1973), p. 45; F. Savater, «Nietzsche, la escuela de Frankfurt, Mayo 68...»: Triunfo 541 (10.2.1973), p. 39; F. Savater, «La práctica de una teoría crítica»: Triunfo 557 (2.6.1973), p. 51; F. Savater, «T. W. Adorno: esplendor y miseria de la filosofía universitaria», en Apología del Sofista, cit., pp. 43-59.

45. F. Savater, «Prólogo» a F. Nietzsche, Inventario, cit., p. 10. 
posible de sistematizar en la forma de una doctrina de manual. Se sigue en esto a Bataille, que, resaltando su incompatibilidad con el fascismo, veía a Nietzsche como un dédalo antes que como una directiva ${ }^{46}$.

Por esta misma razón, Savater rechaza reiteradamente su pertenencia a una posible escuela «neonietzscheana $»^{47}$. Esta etiqueta no es sino una fabricación falsa y artificiosa al servicio de la industria cultural y de la manía taxonómica propia de la pedantería académica, siempre presta a reconocer capillas doctrinales. La propia escritura nietzscheana esquiva la posibilidad de conformar una «escolastica nietzscheana", al modo de lo sucedido con las obras de Marx, escolastizadas como dogma en los partidos comunistas o con las obras de Freud, convertidas en la summa de la Internacional Psicoanalítica.

Savater no duda en utilizar la ironía, la parodia y la provocación a la hora de denunciar lo que considera nimiedades de eruditos («excesivamente pagados de su labor $»^{48}$ ) y gramáticos, incapaces de hacer un uso creativo, auténticamente filosófico de la obra de Nietzsche. Por eso manifiesta ostentosamente su desconocimiento del alemán y su preferencia por la traducción de las Obras Completas de Nietzsche realizada por Eduardo Ovejero y Mauri en Aguilar, reivindica la obra de conservación realizada por la hermana del filósofo o remite, provocativamente a «La voluntad de poder, obra póstuma que recopila importantes inéditos nietzscheanos» ${ }^{49}$; «una obra absolutamente fundamental en el conjunto de la obra nietzscheana y la más influyente en pensadores actuales como Bataille y Klossowski» ${ }^{50}$.

Una de las primeras intervenciones públicas de Savater que tuvo como asunto la filosofía de Nietzsche, tuvo lugar en un ciclo de conferencias sobre el filósofo de Röcken, celebrado en noviembre de 1972 en el Instituto Alemán de Madrid, organizado por este organismo y por el Instituto Fe y Secularidad. Este centro, dirigido entonces por Alvarez Bolado, se fundó en 1968 para hacer viable una de las intenciones más celebradas del concilio Vaticano II; el diálogo del cristianismo con las corrientes europeas contemporáneas, incluidas las tendencias abiertamente ateas. Ya en marzo del mismo año Savater había participado en un

46. J. Le Rider, Nietzsche en France, cit., p. 167.

47. F. Savater, «Klossowski traza un círculo», cit., p. 44; F. Savater, «Cuerpo, amor, silencio»: Triunfo 559 (16-6-1973), p. 49; F. Savater, «El ensayo filosófico en España», en Escritos politeístas, cit., p. 155 (asociando el «invento» con José Luis Abellán). Denuncia asimismo la aparición, en Francia, de una «esclerotizada jerga nietzscheana» que conduce al academicismo (F. Savater, «Prólogo» a F. Nietzsche, Inventario, cit., p. 14). Años después Savater - coincidiendo en esto con Eugenio Trías o Javier Echeverría- reconocerá la pertinencia del rótulo e incluso la existencia de semejante grupo filosófico en España. Cf. F. Savater, «Cuando éramos nietzscheanos»: Revista de Occidente 226 (2000), 53-56, y F. Savater, Mira por dónde, cit., p. 170, y M. Nogueroles Jové, La trayectoria intelectual de Fernando Savater, cit., pp. 30-32.

48. La rehabilitación de Elisabeth en F. Savater, «Nietzsche: vida de un seductor», en Escritos politeístas, cit., p. 86. Aludiendo a una invectiva de Voltaire contra los filólogos, Savater señala que «también puede aplicarse a los empeñosos buscadores de folios perdidos y palabras tachadas que son las moscas del cadáver incorrupto de san Federico» (ibid., p. 96). Como se verá, Savater pronuncia estas palabras en el contexto de una polémica con Sánchez Pascual.

49. F. Savater, "Nietzsche en casa de Circe», en Escritos politeístas, cit., pp. 50-51, y F. Savater, "Nietzsche: vida de un seductor", en ibid., p. 86. Como es sabido, desde la edición emprendida por Colli y Montinari deja de ser legítimo referirse a La voluntad de poder como una obra última e inacabada que Nietzsche habría pretendido escribir; se trataría más bien de un montaje realizado a base de reunir fragmentos póstumos de 1880 (J. Le Rider, Nietzsche en France, cit., p. 206).

50. F. Savater, «Cronología», en F. Nietzsche, Inventario, cit., p. 17. 
encuentro, organizado por las dos instituciones mencionadas, donde se impartieron distintas conferencias sobre la escuela de Frankfurt. En el ciclo consagrado a Nietzsche participaron Álvarez Bolado, Román Gárate, Fernando del Val y Karl Löwith, además del propio Savater. El éxito de público fue espectacular - sólo unos años antes, en 1967, Gonzalo Sobejano resaltaba el escaso interés de los jóvenes españoles por Nietzsche- ${ }^{51}$, aunque también acudió un grupo de gamberros que intentó reventar el acto. En un escrito posterior, Savater calificó de «desafortunada» la contribución de Gárate, porque sostenía, en demérito de Nietzsche, que este menospreciaba al «hombre pequeño» $\mathrm{y}$ a las masas mientras que Marx guardaba una actitud compasiva y solidaria ${ }^{52}$. Respecto al resto de las conferencias se limitó a señalar que "adolecieron, salvo excepción, de academicismo» ${ }^{53}$.

Casi en la misma época (curso 1971-72) tenía lugar en la Universidad Autónoma de Madrid un seminario sobre Nietzsche que suele considerarse como el punto de partida del «neonietzscheanismo español». En este caso, la interacción ritual entre los conferenciantes - la mayoría de ellos con menos de treinta años, como se señala en el volumen que recoge las conferencias- por utilizar los conceptos de Randall Collins, sí produjo una intensa carga de «energía emocional», contribuyendo decisivamente a la sacralización de Nietzsche como pretexto del quehacer filosófico. La clave, según Savater, estaba en la ausencia de academicismo que caracterizó a este Coloquio, su atmósfera distendida, el primado de la «voluntad de estilo» y la transgresión ${ }^{54}$ sobre la camisa de fuerza escolar del comentario de textos. El mismo hecho de que la mayoría de los conferenciantes apenas tuvieran vinculación con la filosofía profesional (Pablo Fernández-Flórez era escritor, Javier Echeverría era entonces sólo matemático, Ángel González García, historiador del arte) se presentaba como emblema de antiacademicismo. Por otro lado el acto se celebró en plena efervescencia política; en octubre de 1971, tres de los profesores que intervinieron en el seminario (Santiago González Noriega, Fernando Savater y Ángel González), considerados como cabecillas del movimiento de penenes, serían expulsados de la Universidad Autónoma arguyendo, entre otras cosas, su negativa a firmar las actas de los exámenes.

Entre los escasos invitados que contaba con más de treinta años cuando se le invitó al seminario, estaba Andrés Sánchez Pascual. Su intervención era sin duda la más atípica del conjunto editado con el título de A favor de Nietzsche. Consistió en la edición y traducción de una selección de textos poéticos de Nietzsche, debidamente introducidos y localizados en su cronología y en el contexto de la producción nietzscheana. Un típico trabajo de filólogo erudito que contrastaba con los excesos de especulación e interpretación libre que conformaban el volumen ${ }^{55}$.

51. G. Sobejano, Nietzsche en España, cit., p. 664. Savater habló de una «asistencia verdaderamente abrumadora» (F. Savater, «El ciclo Nietzsche en el Instituto Alemán», cit., p. 61).

52. F. Savater, «Epílogo de la Apología del sofista», en Apología del sofista, cit., p. 42.

53. F. Savater, «El ciclo Nietzsche en el Instituto Alemán», cit., p. 61.

54. Refiriéndose al tono de las contribuciones, Savater señaló: «Existe en efecto una voluntad de estilo y una violenta afirmación de la instancia sadiana de 'decirlo todo'» (F. Savater, "Nietzsche como pretexto", cit., p. 53).

55. A. Sánchez Pascual, «La poesía de F. Nietzsche», en AA.VV., A favor de Nietzsche, cit., pp. 201-244. En un registro similar se sitúa otro trabajo suyo de esta época, publicado en el monográfico que le consagró a Nietzsche la Revista de Occidente: A. Sánchez Pascual, «Problemas de 'El Anticristo' de Friedrich Nietzsche»: Revista de Occidente 125-126 (1973), 207-240. 
Sin duda, una de las mejores maneras de ilustrar la condición de la lectura savateriana como lectura antiacadémica, consiste en seguir con cierto detalle la relación entablada en esos primeros años setenta, entre Sánchez Pascual —representante de esos católicos doctos que querían entronizar a Nietzsche en el panteón de los filósofos- y Fernando Savater —adalid de un Nietzsche «inenseñable»—.

El filósofo vasco — con motivo de la aparición de Ecce Homo- comienza saludando elogiosamente la iniciativa de Alianza Editorial por arriesgarse a editar en formato de bolsillo las obras principales de Nietzsche ${ }^{56}$. Al mismo tiempo, alaba el esfuerzo de Sánchez Pascual («ha trabajado seis años») por solventar por fin el sempiterno problema de la traducción castellana de las obras del pensador alemán («la mayoría eran traducciones del francés»), beneficiándose de los últimos descubrimientos —en alusión a la empresa de Colli y Montinari- de la crítica textual nietzscheana. Por estas mismas fechas $-\mathrm{y}$ sin duda con la mediación de Savater-Sánchez Pascual era invitado a participar en el seminario de la Autónoma antes mencionado.

En 1972, Andrés Sánchez Pascual colaboraba con Fernando Savater en la edición del texto de Bataille Sobre Nietzsche. Voluntad de suerte. Se encargó de localizar y traducir, con «trabajo paciente y amistoso ${ }^{57}$, las citas batailleanas de las principales obras de Nietzsche. En marzo de 1973, con motivo de la edición en Taurus de una selección de textos de Nietzche («Inventario»), Savater, recurre, por una parte, a las traducciones publicadas en Alianza por Sánchez Pascual y, en el resto y mayoría de los casos (incluyendo numerosas citas de La voluntad de poder), a la versión castellana de Eduardo Ovejero y Mauri. Sánchez Pascual saludó esta edición con una reseña editada en el diario Informaciones de Madrid, acompañada de una andanada de críticas filológicas que tachaban prácticamente de inservibles a las versiones de Ovejero y Mauri ${ }^{58}$. La polémica, recogida en el suplemento del mismo diario, correspondiente a 1973, fue contestada agriamente por Savater y, según constata el profesor José Lázaro, que ha trabajado sobre el asunto, «ambos la recuerdan con amargura ${ }^{59}$.

Sin duda, ecos de esa polémica sobrevivieron poco después en las invectivas de Savater contra las minucias filológicas de los eruditos. En una reseña de la obra de Erwin Rhode, Psyché, Savater parece convertir implícitamente al catedrático Wilamowitz, «erudito poco imaginativo y dogmático» ${ }^{60}$, y recusador absoluto de El origen de la tragedia como obra de valor filológico, en un alter ego de Sánchez Pascual. Wilamowitz, aferrado a detalles filológicos de interés exclusivo para los especialistas contrastaría con Nietzsche -metamorfoseado, sin decirlo, en alter ego del propio Savater, considerado como auténtico filósofo-. Esta antítesis entre el académico y el creador se reproduce en otras intervenciones algo posteriores de Savater sobre Nietzsche ${ }^{61}$. Expresa, más allá de la anécdota del

56. F. Savater, «Y ahora, Nietzsche», cit., p. 55.

57. F. Savater, «Prefacio» a G. Bataille, Sobre Nietzsche. Voluntad de suerte, Madrid: Taurus, 1972, p. 11.

58. Debo la noticia de esta polémica al profesor José Lázaro, que está trabajando con rigor para reconstruirla, dentro de una profunda investigación sobre la obra de Savater. Conste aquí mi agradecimiento.

59. Comunicación personal del doctor José Lázaro.

60. F. Savater, «El alma y los griegos», cit., p. 81.

61. Cf. supra, nota 45. 
desencuentro personal, el modo en que las coacciones estructurales del campo son interiorizadas por los agentes en forma de disposiciones, por muy «lobos esteparios» y creadores ex nibilo que estos se consideren a sí mismos. Tiene que ver también con la contraposición entre una producción filosófica de ciclo corto, esto es, de rápida rentabilidad y dirigida a un público amplio, y una producción de ciclo largo, destinada a una audiencia restringida ${ }^{62}$. Combinando ambas divisiones (académica/creativa, ciclo corto/ciclo largo), se obtienen cuatro posibilidades relevantes ${ }^{63}$ :

\begin{tabular}{|c|c|c|c|c|}
\hline Número & Ciclo Corto & Ciclo Largo & Académica & Creativa \\
\hline 1 & + & - & - & + \\
\hline 2 & - & + & + & - \\
\hline 3 & + & - & + & - \\
\hline 4 & - & + & - & + \\
\hline
\end{tabular}

A partir de estas cuatro posibilidades se pueden clasificar las principales producciones de Savater, correspondientes a los años 1970-1974, que toman como asunto el pensamiento de Nietzsche. La primera posibilidad (1) se correspondería con el género del ensayo divulgativo, tan cultivado por nuestro autor. Aquí pueden emplazarse dos contribuciones: la conferencia citulada «Nietzsche en casa de Circe», pronunciada en un colegio mayor de Zaragoza (febrero de 1973) y el extenso artículo biográfico publicado en la revista Tiempo de historia (diciembre de 1974), titulado «Nietzsche: vida de un seductor». En el primer caso, el formato aparente es el de un comentario de textos, realizado a partir de un fragmento de La Voluntad de poder. Sin embargo, bajo este aspecto escolar y didáctico, lo que se introduce es una reflexión político-moral que toma como asunto la noción de "comunidad sobrehumana» en Nietzsche trayéndola a la actualidad. El segundo texto adopta la fenomenología de la conciencia moral presentada en Así habló Zaratustra (el camello, el león, el niño), para organizar un sumario relato biográfico del propio Nietzsche. Una vez más la aparente descripción escolar sirve a efectos de cuestionamiento crítico; en este caso se pone en entredicho el intento de canonizar académicamente la obra de Nietzsche, resaltando en cambio su condición «inenseñable».

La segunda opción (2) se correspondería con la monografía erudita y especializada, con amplio aparato crítico y destinada sólo a los expertos. Este género no sólo no es frecuentado por Savater sino que aparece en cierto modo descalificado en una obra que afronta el quehacer filosófico con pretensiones de proyección mundana y universal, criticando las tentativas de instalar la división del trabajo en la propia filosofía. El desaliño en las notas, la despreocupación por el uso de las fuentes en su idioma original y un cierto menosprecio de las minucias filológicas son rasgos propios de toda la producción inicial savateriana.

62. Cf. P. Bourdieu, Las reglas del arte. Génesis y estructura del campo literario, Barcelona: Anagrama, 1995, p. 215

63. Obviamente, hemos procedido a «reducir» las posibilidades, teniendo en cuenta la disyunción exclusiva entre los opuestos correspondientes. Sobre esta técnica de las «tablas de verdad», cf. H. S. Becker, Les ficelles du métier. Comment conduire sa recherche en sciences sociales, Paris: La Découverte, 2002, pp. 259-329. 
El tercer caso (3) tiene que ver con la producción de obras escolares de divulgación, como sucede con el género del manual o de la «introducción» al pensamiento de un autor. Aunque en esta época el prejuicio antiescolar de Savater parece haberle alejado de este formato, en los años sucesivos parece no haberle hecho ascos. Así sucede por ejemplo con su participación en el manual de Historia de la Filosofía (destinado a alumnos de COU, publicado en 1978 por la editorial Noguer). En este mismo registro se sitúa Conocer Nietzsche y su Obra, publicada por Savater en 1977, dentro una colección de divulgación escolar vinculada a la editorial Dopesa.

El último caso (4) hace referencia a un tipo de ensayo más vanguardista, con mayor voluntad de estilo y de experimentación formal. Esto lo hace menos accesible y restringe el público que puede acceder al mismo. Aunque en su conjunto la obra de Savater se inclina por el artículo periodístico o por un tipo de ensayo filosófico de amplia divulgación, algunos de sus escritos sobre Nietzsche, editados en este periodo de juventud, llevan esta impronta experimental, como si quisieran, a su modo emular el Nietzsche y el círculo vicioso de Klossowski, que constituye, para el Savater de estos año, el ejemplo por excelencia de exploración creativa «a partir» de Nietzsche.

En este género entraría a formar parte, en primer lugar, su intervención en el ciclo Nietzsche organizado por el Instituto Alemán de Madrid. En vez de vertebrarse convencionalmente, como una exégesis de la obra del pensador alemán, Savater opta por un formato más audaz. Recurriendo a la personificación y a la dramatización, simula que es el propio Nietzsche («Federico, el Anticristo») el que se dirige al auditorio pronunciando un discurso, al modo de un sofista dirigiéndose a los ciudadanos de Atenas. En su plática desmonta el supuesto «ateísmo» e inmoralismo que circula en la modernidad en curso: cientificismo, marxismo, anarquismo, contracultura, mostrando su adherencia al viejo monoteísmo. Se trata asimismo de una «burla», como señala el propio Savater, de los «comentarios pacíficamente eruditos ${ }^{64}$ que se refieren a Nietzsche desde fuera, es decir, de un modo que el propio pensador de Röcken nunca utilizó.

En esta misma estela de la búsqueda experimental se encuadra la contribución de Savater al seminario, ya mencionado, celebrado en la Universidad Autónoma de Madrid, titulada «Cincuenta palabras de Federico Nietzsche»" ${ }^{6}$. Se trata de una suerte de terminología filosófica al estilo de la adorniana, presentada en orden alfabético. Cada entrada («afirmación», «antropocentrismo», «calumnias», «camaradas», etc.) se abre con un fragmento de Nietzsche mínimamente identificado (se indica la obra de procedencia sin añadir ninguna otra precisión). Sigue a continuación un comentario libre, que da expresión al propio pensamiento y a las propias obsesiones de Savater.

Por una homología de posición entre el campo filosófico francés y el español, Savater se ocupa de desautorizar las lecturas eruditas francesas que apuntan a «sistematizar» el pensamiento nietzscheano. Cuestiona por ello el libro de Jean Granier, no ya por su falta de imaginación, sino porque la tentativa de «canonizar» a Nietzsche traduce la voluntad de hacerlo «presentable», integrable en

64. F. Savater, «Apología del sofista», en Apología del sofista, cit., p. 32.

65. F. Savater, "Cincuenta palabras de Federico Nietzsche», en AA.VV., A favor de Nietzsche, cit., pp. 133-176. 
el orden establecido, desprovisto así de su complicidad con la violencia de las «fuerzas heterogéneas» que se revelan en sus textos. Nietzsche se convierte así en un producto más de la industria cultural, inserto en «la miseria de una cultura estereotipada ${ }^{66}$. Se impone entonces una tarea que aúna la vanguardia estética con la vanguardia política; se trata de escribir, no sobre Nietzsche, sino a partir de Nietzsche. Esta voluntad se expresa en la bibliografía ${ }^{67}$ seleccionada, donde se dejan a un lado las monografías académicas de Fink, Lowith y Jaspers, figurando en primera fila los trabajos de Bataille (el Sobre Nietzsche y La experiencia interior), el Nietzsche de Deleuze, el brevísimo Marx, Nietzsche, Freud, de Foucault, el colectivo En favor de Nietzsche; un texto de Trías (La dispersión) y otro de Gómez Pin (de usía a manía). Por encima de todos ellos se dictamina: «el experimento de Klossoski es el más logrado» ${ }^{68}$.

\section{CONCLUSIÓN: UN NIETZSCHE POLÍTICO}

La convergencia entre vanguardismo estético y vanguardismo político en los años del postmayo francés se manifiesta en la descalificación savateriana del Nietzsche canonizado por la academia. Más allá de las preocupaciones ontológicas e incluso de la crítica de la cultura, lo que le interesa de Nietzsche a Savater son sus virtualidades para imaginar otra comunidad. Esta interrogación política era ya la que había presidido la lectura de Bataille en el contexto, bien diferente, de una democracia francesa devaluada y de la potencia emergente del comunismo y de los fascismos. ¿Cómo imaginar una comunidad que no se fundamente en la individualidad del liberalismo burgués (incapaz de superar los desgarramientos sociales) pero tampoco en el Estado stalinista, excluyentes ambos de lo heterogéneo?; ¿cómo evitar también la alianza de las fuerzas heterogéneas con las potencias homogéneas del Estado, como sucede en los fascismos? Estas eran las preguntas de Bataille, y su respuesta pasaba por la referencia a una comunidad «infinita» y «acéfala», esto es, no constituida por individualidades terminadas, limitadas, sino por seres en permanente incompletud y desgarramiento, por individualidades disueltas, trágicas ${ }^{69}$.

La invocación savateriana de una comunidad sustentada en la lucidez de Cioran, esto es, en la experiencia de la inanidad del ser, de la ausencia de fundamento, sigue una estela similar. Implica un rechazo de la democracia liberal ${ }^{70}$ - cuyo correlato filosófico identifica con la filosofía analítica, de creciente predicamento en España - y de la democracia popular — cuyo trasunto filosófico sería la escolástica soviética一. Frente a la comunidad del «yo debo», donde la particularidad se somete al imperativo moral universal, o a la del "yo quiero», donde el individuo se entrega a su diferencia convirtiéndola en ley (se trata de la

66. F. Savater, «Prólogo» a F. Nietzsche, Inventario, cit., pp. 10-11.

67. Ibid., p. 19.

68. Ibid., p. 14.

69. Cf. los excelentes trabajos de A. Campillo, "Georges Bataille: la comunidad infinita», en G. Bataille, El Estado y el problema del fascismo, Valencia: Pre-Textos, 1993, pp. VII-XXV, y Contra la economía. Ensayos sobre Bataille, Granada: Comares, 2001.

70. Cf. la crítica del individualismo en F. Savater, «Nietzsche en casa de Circe», cit., p. 52. 
moral del «héroe»), Savater remite a la comunidad del «yo soy», que suprime a la vez la particularidad de la diferencia (disolviendo la individualidad) y la universalidad de la ley (rebelándose contra toda autoridad trascendente). Esta comunidad es la que correspondería a una «política sobrehumana», como la imaginada por Nietzsche ${ }^{71}$.

Este profetismo savateriano es el que se expresa también en su apelación a una «revolución» que concierne a la vida en su conjunto y no meramente a las estructuras socioeconómicas. Es una revolución que no opone al individuo frente al Estado sino que afecta a la transformación-disolución de la propia individualidad; concierne, por otro lado, no a un sujeto revolucionario único, el proletariado, sino a una subjetividad fragmentada en multitudes diversas (ecologistas, pacifistas, presos, mujeres, enfermos mentales, minorías étnicas, homosexuales, etc.). El Savater de la segunda mitad de los setenta se comprometería con estas iniciativas (antipsiquiatría, legalización de las drogas, lucha anticarcelaria, abolición del servicio militar) ${ }^{72}$. La crítica social se transmuta entonces en una crítica artística $^{73}$ que cuestiona no tanto la explotación económica como el empobrecimiento de las posibilidades vitales bajo las condiciones del capitalismo, sea este de mercado o de Estado. Esta es la implicación política concreta de un nietzscheanismo de izquierdas, sin entrar en la vieja polémica, reavivada por un texto reciente ${ }^{74}$, de si semejante opción tiene o no fundamento in re, esto es, en los propios textos de Nietzsche. Que el destino de esa alternativa, una vez pasada la resaca del postmayo y con la caída de los regímenes comunistas, haya desembocado en una crítica anarconeoliberal del Estado social, no permite sin más incluir a Savater en esa pendiente. Pero esto es algo que hemos tratado en otro lugar ${ }^{75}$.

71. F. Savater, «Nietzsche en casa de Circe», cit., pp. 56-58. Sobre el asunto de la «comunidad» en Nietzsche, cf. M. Barrios, La voluntad de poder como amor, Madrid: Arena Libros, 2006, pp. $149-152$.

72. Sobre la implicación de Savater en el anarquismo libertario y en relación con esas luchas, cf. el espléndido análisis de M. Nogueroles Jové, La trayectoria intelectual de Fernando Savater, cit., pp. 112-158.

73. Sobre estos dos tipos de crítica, cf. L. Boltanski y E. Chiapello, Le nouvel esprit du capitalisme, Paris: Gallimard, 1999, pp. 244-249.

74. N. González Varela, Nietzsche contra la democracia. El pensamiento político de Friedrich Nietzsche (1862-1872), Barcelona: Montesinos, 2010, p. 77.

75. F. Vázquez García, La Filosofía española, cit., pp. 315-336. 